\title{
Trauma Surgery $\&$ Acute Care Open \\ Clinical outcomes following major trauma for patients with a diagnosis of depression: a large UK database analysis
}

\author{
Jamie Large (1) , 'David N Naumann, ${ }^{1}$ Jodie Fellows, ${ }^{2}$ Clare Connor, ${ }^{3}$ Zubair Ahmed ${ }^{1,4}$
}

'Institute of Inflammation and Ageing, University of Birmingham, Birmingham, UK 2University Hospitals

Birmingham NHS Foundation Trust, Birmingham, UK ${ }^{3}$ Aneurin Bevan University Health Board, Newport, UK ${ }^{4}$ NIHR Surgical Reconstruction Microbiology Research Centre, Birmingham, UK

Correspondence to Jamie Large; jxl1005@bham. ac.uk

Received 10 August 2021 Accepted 21 November 2021

(c) Author(s) (or their employer(s)) 2021. Re-use permitted under CC BY-NC. No commercial re-use. See rights and permissions. Published by BMJ.

To cite: Large J,

Naumann DN, Fellows J, et al. Trauma Surg Acute Care Open 2021:6:e000819.

\begin{abstract}
Background More than a quarter of the UK population are affected by depression during their lifetime. For major trauma patients, postinjury depression can result in poorer long-term outcomes, but there is limited evidence regarding outcomes for patients with pre-existing depression. This study investigated the relationship between a diagnosis of depression prior to hospital admission and clinical outcomes after major trauma. Methods Trauma patients at a UK major trauma center were identified during a 6.5-year period using the Trauma Audit and Research Network database. Patients with Injury Severity Score $>15$ who did not die in the emergency department (ED) were included. Logistic regression models were used to compare in-hospital mortality (excluding ED), requirement for surgery, and length of stay (LOS) between those with depression and those without.

Results There were 4602 patients included in the study and $6.45 \%$ had a diagnosis of depression. Depression was associated with a significant reduction in mortality (OR 0.54, 95\% Cl 0.30 to 0.91; $p=0.026$ ). However, patients with depression were more likely to have longer LOS (OR 124, 95\% Cl 8.5 to $1831 ; \mathrm{p}<0.001)$ and intensive care unit LOS (OR 9.69, 95\% Cl 3.14 to 29.9; $\mathrm{p}<0.001)$. Patients with depression were also more likely to undergo surgery $(\mathrm{OR} 1.36,95 \% \mathrm{Cl} 1.06$ to 1.75 ; $\mathrm{p}=0.016$ )

Discussion A pre-existing diagnosis of depression has complex association with clinical outcomes after major trauma, with reduced mortality but longer LOS and higher likelihood of surgical intervention. Further prospective investigations are warranted to inform optimal management strategies for major trauma patients with pre-existing depression. Level of evidence III.
\end{abstract}

\section{INTRODUCTION}

Depression is the most commonly diagnosed mental health condition and is a leading cause of global morbidity. ${ }^{1}$ In the UK, over a quarter of the population will at some point be affected by depression, ${ }^{2}$ and there is an estimated prevalence of $11 \% .^{3}$ More recently, the proportion of people experiencing depression has been exacerbated by the global COVID-19 pandemic, with a systematic review reporting a global prevalence of $33.7 \%$ during the study period up until May $2020 .{ }^{4}$ Similarly, the UK Office for National Statistics reported that $19.2 \%$ of adults exhibited symptoms of depression during June 2020.5 Considering the current increase in depression, it is essential to understand how depression might impact on patient outcomes after injury.

Depression is a well-documented adverse outcome after major trauma which can result in significant disability and reduced quality of life. ${ }^{6-10}$ Efforts have been made to mitigate the risk factors which lead to postinjury depression. ${ }^{11-13}$ However, there is a relative sparsity of evidence regarding preinjury depression and its relationship with in-hospital outcomes after major trauma. There are suggestions that major trauma patients with depression have worse postoperative complications, ${ }^{14}$ and that there may be associations with in-hospital outcomes such as mortality and length of stay (LOS), but most studies have not looked at major trauma. ${ }^{15-20}$ Therefore, specific studies of the major trauma population are warranted because they are likely to have different outcomes and care requirements compared with those suffering minor trauma, and risk factors are not always applicable to both groups. ${ }^{21}$ Although studies have investigated the impact of any mental health difficulties as a whole on the outcomes after injury, ${ }^{22} 23$ it cannot be assumed that all mental health difficulties will affect in-hospital outcomes in the same way.

There are conflicting reports in the literature regarding whether depression is a risk factor for in-hospital mortality in any subset of trauma patients. Whereas one study among the general trauma population suggested that depression is a risk factor for mortality, ${ }^{18}$ two further studies in orthopedic trauma populations demonstrated a reduction in mortality among patients with depression. ${ }^{1720}$ Due to this uncertainty, an examination of a large population of major trauma patients is warranted.

The current study aimed to investigate the relationship between a pre-existing diagnosis of depression and clinical outcomes in patients after major trauma. We hypothesized that patients with depression were more likely to have poorer clinical outcomes overall.

\section{METHODS}

\section{Study design}

A retrospective observational study was undertaken using the prospectively recorded Trauma Audit and Research Network (TARN) database for a single major trauma center (MTC) in the West Midlands (University Hospitals Birmingham NHS Foundation Trust) 


\section{Patient selection}

Data were requested from the TARN database for all trauma patients at the University Hospitals Birmingham NHS Foundation Trust's MTC admitted between January 1, 2014 and July 31, 2020 with an Injury Severity Score (ISS) greater than 15. The TARN database includes patients who fulfill certain LOS criteria and must have at least one of the following: $\geq 3$ overnight stays in hospital, critical care admission, hospital transfer or repatriation where there is a total of $\geq 3$ overnight stays, or death. ${ }^{24}$ For the current study, patients from the database who died in the emergency department (ED) or who had insufficient data for the study criteria were excluded $(n=121)$.

\section{Data collection}

The following data were extracted from the TARN database: patient demographics (including medical history and medication history, age and gender), injury characteristics at admission (ISS, regional Abbreviated Injury Scale (AIS) score, Glasgow Coma Scale (GCS) score), and clinical outcome data. A Charlson Comorbidity Index (CCI) score was created from patients' documented medical history. ${ }^{25}$ Electronic records were also searched for confirmation of data acquired from TARN.

A history of depression, irrespective of treatment, has been identified as a risk factor in previous study populations. ${ }^{16} 1819$ Therefore, data on treatment were not collected in the current study, and patients were categorized as having a pre-existing diagnosis of depression if they had a recorded history of depression within the TARN database. Medical history is a compulsory field within the TARN database; a pre-existing diagnosis of depression is recorded when a clinician has documented a medical history of depression in a patient's clinical noting. Anonymized data were collated and stored on an encrypted National Health Service (NHS) computer database.

\section{Clinical outcomes}

The outcomes of interest in the current study were taken directly from the TARN data and included in-hospital mortality (excluding ED), LOS, LOS in the intensive care unit (ICU), ICU admission, requirement for surgery, and number of operations.

\section{Data analysis}

Data are presented as number and percentage for categorical data and median and IQR for continuous data. Fisher's exact test and $\chi^{2}$ test were used for comparison of categorical data as appropriate, and Mann-Whitney $\mathrm{U}$ test was used to compare continuous data. Logistic regression models were used to determine the OR and 95\% CI for each clinical outcome using a preexisting diagnosis of depression as an independent variable. The other independent variables in the models were chosen a priori as clinically relevant factors and included age, gender, ISS, GCS score, and CCI. A p value of $<0.05$ was considered statistically significant. Statistical analysis and graph generation were performed using GraphPad Prism V.9.1.0 (GraphPad Software, San Diego, California, United States of America) and R (R Foundation for Statistical Computing, Vienna, Austria).

\section{RESULTS}

\section{Patient and injury characteristics}

There were 4723 major trauma patients identified during the study period, and after exclusions this gave a study cohort of 4602 included patients. The median age of the total study population was 55 (IQR 34-76) years and 72.9\% were male. Patients with pre-existing depression accounted for 297 of 4602 (6.45\%)

\begin{tabular}{|c|c|c|c|}
\hline Baseline characteristics & $\begin{array}{l}\text { No depression } \\
(n=4305)\end{array}$ & $\begin{array}{l}\text { Pre-existing } \\
\text { depression } \\
(\mathrm{n}=297)\end{array}$ & $P$ value \\
\hline Age, median (IQR) years & $56(33-76)$ & $51(38-67)$ & $0.015^{*}$ \\
\hline Male, n (\%) & $3158(73)$ & $195(66)$ & $0.005 \dagger$ \\
\hline CCl, median (IQR) & $1(0-4)$ & $1(0-3)$ & $0.001^{*}$ \\
\hline ISS, median (IQR) & $25(18-29)$ & $25(18-29)$ & 0.929 \\
\hline GCS score, median (IQR) & $15(11-15)$ & $15(13-15)$ & 0.326 \\
\hline \multicolumn{4}{|c|}{ Most severely injured organ, $n$ (\%) } \\
\hline Head & $2465(57)$ & $153(52)$ & 0.098 \\
\hline Chest & $671(16)$ & $46(15)$ & \\
\hline Abdomen & $86(2)$ & $4(1)$ & \\
\hline Limbs & $329(8)$ & $26(9)$ & \\
\hline Multiple & $560(13)$ & $53(18)$ & \\
\hline Spine & $162(4)$ & $10(3)$ & \\
\hline Other & $32(1)$ & $5(2)$ & \\
\hline \multicolumn{4}{|l|}{ Mechanism of injury, $\mathrm{n}(\%)$} \\
\hline Blast & $7(0)$ & $0(0)$ & $<0.001 \ddagger$ \\
\hline Blow(s) without weapon & $321(7)$ & $27(9)$ & \\
\hline Burn & $4(0)$ & $1(0)$ & \\
\hline Crush & $32(1)$ & $1(0)$ & \\
\hline Fall from less than $2 \mathrm{~m}$ & $1751(41)$ & $110(37)$ & \\
\hline Fall from more than $2 \mathrm{~m}$ & $512(12)$ & $62(21)$ & \\
\hline Road traffic collision & $1403(33)$ & $63(21)$ & \\
\hline Gunshot wound & $32(1)$ & $4(1)$ & \\
\hline Stabbing & $195(5)$ & $21(7)$ & \\
\hline Other & $48(1)$ & $8(3)$ & \\
\hline
\end{tabular}

*Statistically significant using Mann-Whitney U test.

†Statistically significant using Fisher's exact test.

\#Statistically significant using $\chi^{2}$ test.

CCI, Charlson Comorbidity Index; GCS, Glasgow Coma Scale; ISS, Injury Severity Score.

patients in the study cohort. There was a median CCI of 1 (IQR 0-4). The median ISS was 25 (IQR 18-29) and the median GCS score was 15 (IQR 12-15).

Patient characteristics were compared between those with depression and those without depression in table 1. Patients with depression were significantly more likely to be younger (median age: 51 (IQR 38-67) years vs. 56 (IQR 33-76) years; $\mathrm{p}=0.015$ ) and female (44\% vs. $37 \% ; \mathrm{p}=0.005)$ and were less likely to have significant comorbidities (median CCI: 1 (IQR 0-4) vs. 1 (IQR $0-3) ; \mathrm{p}=0.001)$. Whereas differences existed in patient demographics, there were no significant differences in injury characteristics at baseline (table 1).

\section{Univariate analysis}

Overall, the absolute risk of mortality was 0.126 (95\% CI 0.117 to 0.136$)$. In total, $50.5 \%$ of patients were admitted to ICU and the median ICU LOS was 1 (IQR 0-5) day, whereas the median hospital LOS was 13 (IQR 6-26) days. Surgical intervention was performed for $51.9 \%$ of patients and the median number of operations was 1 (IQR 0-1). Before adjusting for baseline characteristics, depression was associated with increased LOS and ICU LOS, but a decrease in mortality (table 2 and figure 1). 
Table 2 Association of depression with mortality, ICU admission, LOS, ICU LOS, and surgical intervention before adjustment for confounding factors

\begin{tabular}{lccr}
\hline Outcome & $\begin{array}{l}\text { No depression } \\
(\mathrm{n}=4305)\end{array}$ & $\begin{array}{l}\text { Pre-existing depression } \\
(\mathrm{n}=297)\end{array}$ & P value \\
\hline Mortality, n (\%) & $562(13)$ & $20(7)$ & $0.001^{*}$ \\
\hline ICU admission, n (\%) & $2162(50)$ & $160(54)$ & 0.231 \\
$\begin{array}{l}\text { LOS, median (IQR) days } \\
\text { Intensive care unit }\end{array}$ & $1(0-5)$ & $1(0-8)$ & $0.022 \dagger$ \\
$\quad$ Hospital & $13(6-25)$ & $18(9-34)$ & $<0.001 \dagger$ \\
Needed surgery, n (\%) & $2214(51)$ & $175(59)$ & $0.014^{*}$ \\
\hline
\end{tabular}

*Statistically significant using Fisher's exact test.

tStatistically significant using Mann-Whitney U test.

ICU, intensive care unit; LOS, length of stay.

\section{Multivariate analysis}

Mortality

Using the logistic regression model, it was determined that increased age, CCI, ISS, and reduced GCS score were all significantly associated with increased mortality (table 3). However, among patients with a history of depression, there was a statistically significant reduction in mortality (OR $0.54,95 \%$ CI 0.30 to $0.91 ; \mathrm{p}=0.026$ ).

\section{Hospital and ICU episodes}

Figure 2 demonstrates the monthly hospital and ICU admissions for major trauma patients throughout the study period. Longer hospital and ICU LOS were associated with increased ISS and age and reduced GCS score (table 4). Male gender was associated with prolonged ICU LOS but not in-hospital LOS, and a higher CCI was associated with a reduction in ICU LOS (table 4). Depression was not found to be a risk factor for admission to ICU (OR 1.09, 95\% CI 0.94 to 1.23 ; p=0.311). However, depression was associated with a significantly longer ICU LOS (OR 9.69, 95\% CI 3.14 to 29.9; p<0.001). Similarly, depression was strongly associated with longer in-hospital LOS (OR $124,95 \%$ CI 8.5 to $1831 ; \mathrm{p}<0.001$ ).

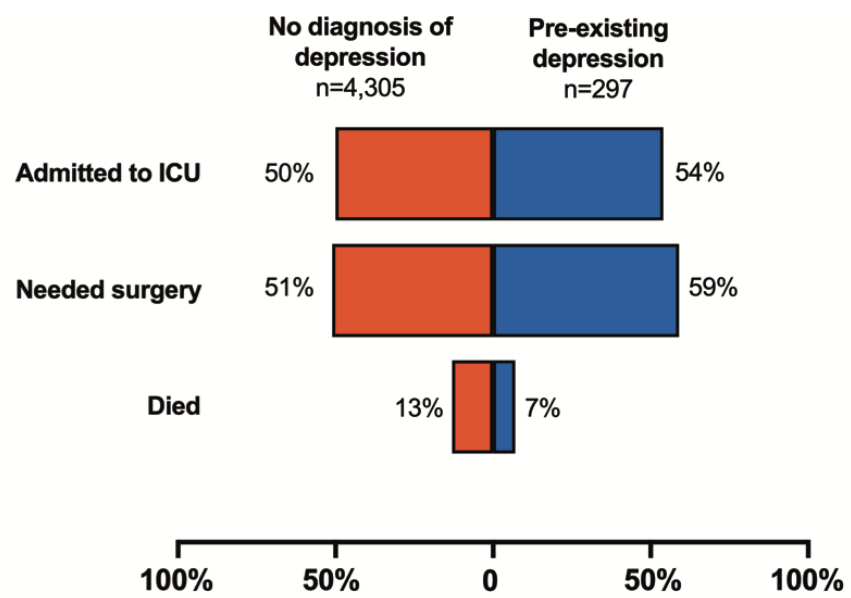

Figure 1 Mortality, admission to intensive care unit (ICU), and operative intervention compared between those with and without a pre-existing diagnosis of depression.
Table 3 Associations of baseline characteristics with mortality in the regression analysis

\begin{tabular}{lllc}
\hline Baseline characteristics & OR & $95 \% \mathrm{Cl}$ & P value \\
\hline Pre-existing depression & 0.54 & 0.30 to 0.91 & $0.026^{*}$ \\
CCI & 1.21 & 1.10 to 1.34 & $<0.001^{*}$ \\
Age & 1.04 & 1.03 to 1.05 & $<0.001^{*}$ \\
Male gender & 1.14 & 0.89 to 1.45 & 0.303 \\
ISS & 1.04 & 1.03 to 1.05 & $<0.001^{*}$ \\
GCS score & 0.74 & 0.72 to 0.76 & $<0.001^{*}$ \\
\hline
\end{tabular}

* Indicates statistical significance.

CCI, Charlson Comorbidity Index; GCS, Glasgow Coma Scale; ISS, Injury Severity Score.

Operative intervention

Patients with depression were significantly more likely to undergo surgical intervention (OR $1.36,95 \%$ CI 1.06 to 1.75 ; $\mathrm{p}=0.016$ ), and operative intervention was also more likely in younger and in male patients with higher ISS and higher GCS score (table 5).

\section{DISCUSSION}

To our knowledge, this study is the first to investigate the relationship between pre-existing depression and mortality, LOS, ICU LOS, or operative intervention after major trauma, as defined by ISS $>15$. A history of depression was associated with a reduced OR for mortality in our study, which matched for comorbidities, age, gender, injury severity, and GCS score. However, depression was associated with significantly longer stay in hospital and ICU.

Our data are in contrast to studies in non-trauma populations which generally associate depression with increased mortality. ${ }^{26}$ However, two studies of orthopedic trauma patients have also reported reduced mortality in patients with depression. ${ }^{17} 20$ Our LOS findings are in keeping with prior evidence that identified depression as a risk factor for LOS and ICU LOS. ${ }^{15-17} 19$ Increased LOS in hospital and ICU may reflect impaired functional recovery, which is also in keeping with previous reports that patients who develop depression after injuries have impaired long-term functional recovery. ${ }^{7} 2$ Since long ICU stays may be associated with increased complication rates, ${ }^{28}$ and poorer longterm morbidity and mortality, ${ }^{29}$ a history of depression should serve as an important prognostic indicator and might alert

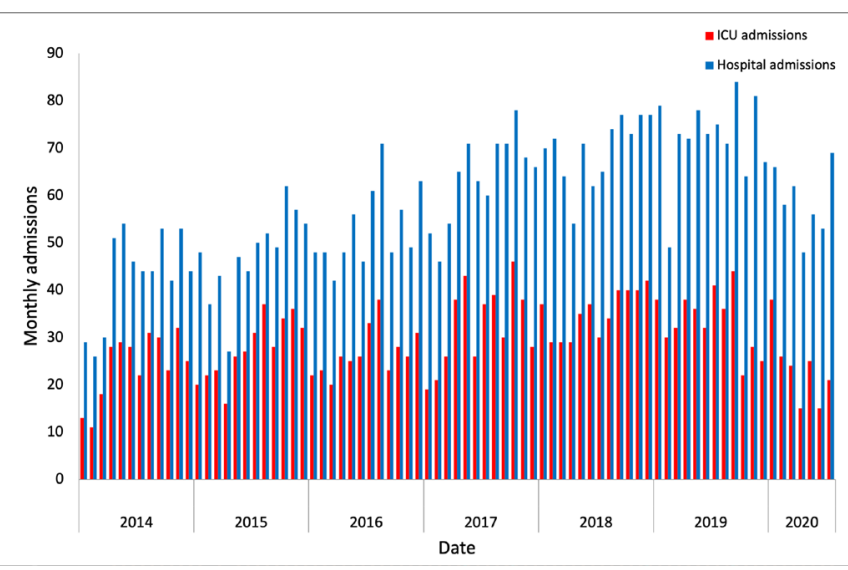

Figure 2 Monthly hospital and intensive care unit (ICU) admissions for major trauma patients during the study period. 
Table 4 Association of baseline characteristics with LOS and ICU LOS in the regression analysis

\begin{tabular}{llll}
\hline Baseline characteristics & $\begin{array}{l}\text { Admission to ICU } \\
\text { OR, } 95 \% \mathrm{Cl} ; \boldsymbol{p} \text { value }\end{array}$ & $\begin{array}{l}\text { ICU LOS } \\
\text { OR, } 95 \% \mathrm{Cl} ; \boldsymbol{p} \text { value }\end{array}$ & $\begin{array}{l}\text { In-hospital LOS } \\
\text { OR, } 95 \% \mathrm{Cl} ; \boldsymbol{p} \text { value }\end{array}$ \\
\hline Pre-existing depression & $1.09,0.94$ to $1.23 ; 0.311$ & $9.69,3.14$ to $29.9 ; 0.001^{*}$ & $124,8.5$ to $1831 ; 0.001^{*}$ \\
CCl & $0.79,0.73$ to $0.85 ;<0.001^{*}$ & $0.49,0.36$ to $0.65 ;<0.001^{*}$ & $0.65,0.33$ to $1.30 ; 0.224$ \\
Age & $1.00,0.99$ to $1.00 ; 0.476$ & $1.03,1.01$ to $1.06 ; 0.011^{*}$ & $1.07,1.00$ to $1.14 ; 0.030^{*}$ \\
Male gender & $1.19,1.01$ to $1.41 ; 0.033^{*}$ & $2.63,1.37$ to $5.05 ; 0.004^{*}$ & $1.55,0.32$ to $7.36 ; 0.584$ \\
ISS & $1.08,1.07$ to $1.09 ;<0.001^{*}$ & $1.26,1.21$ to $1.30 ;<0.001^{*}$ & $1.44,1.33$ to $1.56 ;<0.001^{*}$ \\
GCS score & $0.80,0.78$ to $0.82 ;<0.001^{*}$ & $0.84,0.77$ to $0.90 ;<0.001^{*}$ & $0.57,0.48$ to $0.69 ;<0.001^{*}$ \\
\hline
\end{tabular}

*Indicates statistical significance.

CCI, Charlson Comorbidity Index; GCS, Glasgow Coma Scale; ICU, intensive care unit; ISS, Injury Severity Score; LOS, length of stay.

clinicians to anticipate the requirement for additional support with rehabilitation.

Depression is also associated with increased perception of pain, ${ }^{30}$ which may impair patients' ability to mobilize and engage with physical therapy, ${ }^{31}$ possibly contributing to this impaired functional recovery and delayed discharge. ${ }^{31}{ }^{32}$ There is also evidence that patients with depression are more likely to have poorer health behaviors, such as smoking and physical inactivity, ${ }^{33}$ which may predispose them to complications and increased LOS. ${ }^{34}$ Thus, the influence of pain perception and health behaviors on the functional recovery of trauma patients with depression warrants further investigation.

It is common for trauma patients to develop new depressive symptoms when admitted to ICU, ${ }^{35}$ and trauma patients are at high risk of delirium during both hospital and ICU stays. ${ }^{36}$ It seems likely that the impact of ICU stays on mental health may be greater for patients with pre-existing mental health difficulties and may therefore require more prolonged management. These patients may require additional input from other services including psychiatry, psychology, and occupational health to support their onward recovery. Although this prolonged multidisciplinary care would increase LOS, this may contribute to the improved mortality observed in this study, since a multidisciplinary approach to care may improve mortality among critically ill patients. ${ }^{37}$ The effect of a multidisciplinary approach to trauma is an important area of research and interventional studies are needed to investigate the effect on mortality and functional recovery.

There is a possible biological mechanism for the associations observed in this study. It is increasingly recognized that the immuno-inflammatory response plays an important role in trauma. ${ }^{38} \mathrm{~A}$ deranged inflammatory response may result in potentially fatal complications such as multiple organ failure and adult respiratory distress syndrome. ${ }^{39}$ In depression, there is an increase in proinflammatory cytokines as well as changes

Table 5 Association of baseline characteristics with operative intervention in the regression analysis

\begin{tabular}{lllc}
\hline Baseline characteristics & OR & $95 \% \mathrm{Cl}$ & P value \\
\hline Pre-existing depression & 1.36, & 1.06 to 1.75 & $0.016^{*}$ \\
\hline $\mathrm{CCl}$ & 1.02 & 0.95 to 1.08 & 0.622 \\
Age & 0.98 & 0.98 to 0.99 & $<0.001^{*}$ \\
Male gender & 1.19 & 1.03 to 1.37 & $0.020^{*}$ \\
ISS & 1.04 & 1.03 to 1.04 & $<0.001^{*}$ \\
GCS score & 1.04 & 1.02 to 1.06 & $<0.001^{*}$ \\
\hline
\end{tabular}

*Indicates statistical significance.

CCI, Charlson Comorbidity Index; GCS, Glasgow Coma Scale; ISS, Injury Severity Score. to the hypothalamic-pituitary-adrenal axis. ${ }^{40}$ Indeed, when Weinberg et al ${ }^{14}$ identified increased postoperative complication rates in orthopedic trauma populations, it was suggested that this may have been the result of an increased acute inflammatory response. However, our finding of reduced mortality in patients with depression does not support this hypothesis and it is possible that more complex differences in the acute inflammatory response may contribute to the outcomes observed in this study. Differences in the inflammatory response to trauma in patients with depression must be assessed in further prospective studies. Such research may have implications for all major trauma patients as identifying possible pathways for immunoinflammatory modulation and could help produce novel treatment options.

Patients with pre-existing depression in our cohort were more likely to undergo operative intervention. It has been demonstrated in non-trauma populations that low self-efficacy can predict reduced participation in treatment decision making, ${ }^{41}$ as well as poorer long-term surgical outcomes. ${ }^{42}$ Considering that depression is associated with low self-efficacy, ${ }^{43} 44$ the increase in operative intervention may be driven by differences in how patients with depression consider and communicate their treatment preferences to clinicians. However, it is not clear from our data whether the differences in operative intervention are due to different patterns of injury, differences in clinicians' propensity to operate, or patients' willingness or capacity to consent to surgery. Nonetheless, in orthopedic trauma, patients with depression are more likely to have postoperative complications ${ }^{14}$; therefore, it is important that further investigations are undertaken to explore why these patients underwent surgical intervention more frequently.

The $6 \%$ of patients identified in our study cohort with a preexisting diagnosis of depression is likely to be lower than the true population prevalence. ${ }^{2} 3$ The underidentification of patients with depression in trauma has also been reported by other studies, with one study suggesting that $30.2 \%$ of depression diagnoses have been missed during patient assessment. ${ }^{14}$ Since the true prevalence of depression was likely underdiagnosed in the current study, there may be some selection bias according to how detailed a history was available during initial presentation. In trauma, a thorough history may prevent missed injuries which would otherwise increase mortality if left undiagnosed. ${ }^{45}$ Additionally, knowledge of previous medications and comorbidities is important for guiding appropriate treatment. It is unknown whether the quality of the clinicians' history might have influenced the results and there is a paucity of literature examining the effect of accurate history taking on trauma mortality. Moreover, although depression is recorded by TARN, it may not be asked about routinely by the treating clinician. Therefore, investigation is needed to identify whether inclusion of depression 
as a predefined field within prehospital or ED proformas can enable better identification of these patients and whether this may improve patients' outcomes.

The effect of antidepressant medication on patients' outcomes is currently an area of debate. Whereas some studies suggest that antidepressants may increase surgical complications, ${ }^{46}$ others suggest that this is probably mediated by depression itself rather than the antidepressant medications. ${ }^{47}$ For orthopedic trauma patients, Weinberg et $a^{14}$ reported that prescribing antidepressant medication to patients with depression did not affect surgical complication rates. ${ }^{14}$ However, a further study in orthopedic trauma suggested that delays to prescribing antidepressant medication may mediate increased LOS by inducing withdrawal symptoms and preventing effective engagement with therapy. ${ }^{15} \mathrm{In}$ major trauma patients, there is little evidence to suggest whether antidepressant medication affects outcomes. Our study did not investigate antidepressant prescription and it is possible that this may have contributed to the outcomes. Further investigations of the effect of antidepressants in major trauma may help identify the optimum pharmacological management of depression.

\section{Limitations}

The most significant limitation of our study methodology is the utilization of a database, with risk of omissions in relevant medical history, including depression. However, TARN is known to be a reliable source of data and is commonly used for similar retrospective cohort studies. ${ }^{21} 4849$ Furthermore, it was not possible to assess the severity of a patient's depression nor how long before the admission they were diagnosed. Additionally, antidepressants may be indicated for other medical conditions and non-pharmacological psychotherapy was not reliably disclosed in clinical records, thus making it impractical to stratify patients based on current treatment. It was therefore not possible to distinguish patients with chronic, well-managed depression from patients with more recent onset, severe or unmanaged depression. Moreover, as previously mentioned, the proportion of patients identified to have depression was lower than expected compared with the UK population. This indicates that some diagnoses of depression are likely to have been missed, which potentially increases the risk of selection bias in this study.

To classify patterns of injury, the mechanisms of injury and AIS scores for each body region were compared between each group. Although there was no significant difference in AIS scores, the groups were not perfectly matched by mechanisms of injury. Although this is an expected limitation of a cohort study design, it is possible that differences in these factors may have influenced the results. Differences in injury patterns may also affect cause of death (such as from hemorrhage or brain injury), but we did not have access to precise causes of death for each patient. The reduced mortality observed in both the current cohort of major trauma patients and two studies of orthopedic trauma populations is conflicting with a study of the general trauma population, but it is unknown what may have caused these differences. ${ }^{17} 1820$ Additionally, although hospital and ICU admissions have varied over time (figure 2), we did not have access to any changes in precise indications for admission to ICU during the study period. Multicentered prospective studies with greater granularity of data may be warranted to better delineate the relationship between outcomes and different levels of severity of depression and different treatment modalities. We were also unable to measure outcomes once patients left the hospital and therefore could not assess longer-term outcomes.

\section{CONCLUSION}

In our database study of 4602 major trauma patients, there was a significant association between a pre-existing diagnosis of depression and survival. Depression was also a significant risk factor for increased hospital and ICU LOS, which may indicate a requirement for additional support with recovery and rehabilitation. There is also an increased incidence of surgical intervention in patients with depression, but it is unclear why. Multicenter prospective investigations should be undertaken to confirm the findings of this study and to identify the underlying mechanisms for these results.

\section{Twitter David N Naumann @DavidNNaumann}

Contributors Conceived and designed the study: JL. Data collection: JL. Statistical analysis: DN. Data interpretation: JL. Drafted the article: JL. Reviewed the article and participated in critical revisions: JL, DN, JF, CC, and ZA. Supervision: DN and ZA. All authors approved the final version of the article. Gaurantor: ZA

Funding The authors have not declared a specific grant for this research from any funding agency in the public, commercial or not-for-profit sectors.

Competing interests None declared.

Patient consent for publication Not required.

Ethics approval Using the National Research Ethics Service Decision Tool, ${ }^{50}$ it was determined that the study did not require specific research ethics committee approval, but local institutional approval was obtained prior to data collection.

Provenance and peer review Not commissioned; externally peer reviewed.

Data availability statement Data are available upon reasonable request.

Open access This is an open access article distributed in accordance with the Creative Commons Attribution Non Commercial (CC BY-NC 4.0) license, which permits others to distribute, remix, adapt, build upon this work non-commercially, and license their derivative works on different terms, provided the original work is properly cited, appropriate credit is given, any changes made indicated, and the use is non-commercial. See: http://creativecommons.org/licenses/by-nc/4.0/.

\section{ORCID iD}

Jamie Large http://orcid.org/0000-0003-4691-4628

\section{REFERENCES}

1 Liu Q, He H, Yang J, Feng X, Zhao F, Lyu J. Changes in the global burden of depression from 1990 to 2017: findings from the global burden of disease study. J Psychiatr Res 2020;126:134-40.

2 Smith DJ, Nicholl BI, Cullen B, Martin D, Ul-Haq Z, Evans J, Gill JMR, Roberts B, Gallacher J, Mackay D, et al. Prevalence and characteristics of probable major depression and bipolar disorder within UK Biobank: cross-sectional study of 172,751 participants. PLoS One 2013;8:e75362.

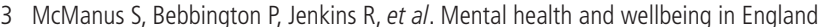
Adult Psychiatric Morbidity Survey 2014 : a survey carried out for NHS Digital by NatCen Social Research and the Department of Health Sciences, University of Leicester. 2016. https://files.digital.nhs.uk/pdf/q/3/mental_health_and_wellbeing_in_ england_full_report.pdf (24 Dec 2020).

4 Salari N, Hosseinian-Far A, Jalali R, Vaisi-Raygani A, Rasoulpoor S, Mohammadi M, Rasoulpoor S, Khaledi-Paveh B. Prevalence of stress, anxiety, depression among the general population during the COVID-19 pandemic: a systematic review and metaanalysis. Global Health 2020;16:57

5 Vizard T, Davis J, White E, et al. Coronavirus and depression in adults, Great Britain - Office for National Statistics. https://www.ons.gov.uk/peoplepopulationandc ommunity/wellbeing/articles/coronavirusanddepressioninadultsgreatbritain/june2020\# main-points (24 Dec 2020).

6 Han PP, Holbrook TL, Sise MJ, Sack DI, Sise CB, Hoyt DB, Coimbra R, Potenza B, Anderson JP. Postinjury depression is a serious complication in adolescents after major trauma: injury severity and injury-event factors predict depression and long-term quality of life deficits. J Trauma 2011;70:923-30.

7 Kellezi B, Coupland C, Morriss R, Beckett K, Joseph S, Barnes J, Christie N, Sleney J, Kendrick $D$. The impact of psychological factors on recovery from injury: a multicentre cohort study. Soc Psychiatry Psychiatr Epidemiol 2017;52:855-66.

8 Nota SPFT, Bot AGJ, Ring D, Kloen P, SPFT N, . Disability and depression after orthopaedic trauma. Injury 2015;46:207-12

9 Crichlow RJ, Andres PL, Morrison SM, Haley SM, Vrahas MS. Depression in orthopaedic trauma patients. prevalence and severity. J Bone Joint Surg Am 2006;88:1927-33.

10 Vranceanu A-M, Bachoura A, Weening A, Vrahas M, Smith RM, Ring D. Psychological factors predict disability and pain intensity after skeletal trauma. J Bone Joint Surg Am 2014;96:e20. 
11 Wegener ST, Pollak AN, Frey KP, Hymes RA, Archer KR, Jones CB, Seymour RB, O'Toole RV, Castillo RC, Huang Y, et al. The trauma collaborative care study (TCCS). J Orthop Trauma 2017;31 Suppl 1:S78-87.

12 Zatzick D, Russo J, Lord SP, Varley C, Wang J, Berliner L, Jurkovich G, Whiteside $\mathrm{LK}, \mathrm{O}^{\prime}$ Connor S, Rivara FP. Collaborative care intervention targeting violence risk behaviors, substance use, and posttraumatic stress and depressive symptoms in injured adolescents: a randomized clinical trial. JAMA Pediatr 2014;168:532-9.

13 Jones $\mathrm{M}$, Acion L, Jorge RE. What are the complications and emerging strategies for preventing depression following traumatic brain injury? Expert Rev Neurother 2017; 17:631-40.

14 Weinberg DS, Narayanan AS, Boden KA, Breslin MA, Vallier HA. Psychiatric illness is common among patients with orthopaedic Polytrauma and is linked with poor outcomes. J Bone Joint Surg Am 2016;98:341-8.

15 Haupt E, Vincent HK, Harris A, Vasilopoulos T, Guenther R, Sharififar S, Hagen JE. Preinjury depression and anxiety in patients with orthopedic trauma and their treatment Injury 2018:49:1079-84

16 Falsgraf E, Inaba K, de Roulet A, Johnson M, Benjamin E, Lam L, Matsushima K, Strumwasser A, Demetriades $D$, et al. Outcomes after traumatic injury in patients with preexisting psychiatric illness. J Trauma Acute Care Surg 2017:83:882-7.

17 Schwartz S, Bazargan-Hejazi S, Pan D, Ruiz D, Shirazi A, Washington E. Association of psychiatric diagnostic conditions with hospital care outcomes of patients with orthopedic injuries. Perm J 2018;22:17-120.

18 Thompson HJ, Rivara FP, Nathens A, Wang J, Jurkovich GJ, Mackenzie EJ. Development and validation of the mortality risk for trauma comorbidity index. Ann Surg 2010;252:370-5.

19 Hong J, Lee W-K, Kim MK, Lee B-E, Shin SD, Park H. Effect of comorbidity on length of hospital stay and in-hospital mortality among unintentionally injured patients. Accid Anal Prev 2013:52:44-50.

20 Menendez ME, Neuhaus V, Bot AGJ, Vrahas MS, Ring D. Do psychiatric comorbidities influence inpatient death, adverse events, and discharge after lower extremity fractures? Clin Orthop Relat Res 2013;471:3336-48.

21 McHale P, Hungerford D, Taylor-Robinson D, Lawrence T, Astles T, Morton B, et al. Socioeconomic status and 30-day mortality after minor and major trauma: a retrospective analysis of the trauma audit and research network (TARN) dataset for England. PLoS One 2018:13:e0210226.

22 Fang J-F, Shih L-Y, Lin B-C, Hsu Y-P. Pelvic fractures due to falls from a height in people with mental disorders. Injury 2008;39:881-8.

23 Wan JJ, Morabito DJ, Khaw L, Knudson MM, Dicker RA. Mental illness as an independent risk factor for unintentional injury and injury recidivism. J Trauma 2006;61:1299-304

24 The Trauma Audit \& Research Network (TARN). The Trauma Audit \& Research Network (TARN) Procedures Manual, England \& Wales. 2021. https://www.tarn.ac.uk/content/ downloads/53/Procedures $\% 20$ manual $\% 20$ England $\% 20 \& \% 20$ Wales $\% 20$ Complete $\%$ 20January\%2021.pdf (15 Feb 2021).

25 Charlson ME, Pompei P, Ales KL, MacKenzie CR. A new method of classifying prognostic comorbidity in longitudinal studies: development and validation. J Chronic Dis 1987; 40:373-83

26 Machado MO, Veronese N, Sanches M, Stubbs B, Koyanagi A, Thompson T, Tzoulaki I, Solmi M, Vancampfort D, Schuch FB, et al. The association of depression and all-cause and cause-specific mortality: an umbrella review of systematic reviews and metaanalyses. BMC Med 2018;16:1-13.

27 Steenbergen S, Rijkenberg S, Adonis T, Kroeze G, van Stijn I, Endeman H. Long-Term treated intensive care patients outcomes: the one-year mortality rate, quality of life, health care use and long-term complications as reported by general practitioners. BMC Anesthesiol 2015:15:142.

28 Ong AW, Omert LA, Vido D, Goodman BM, Protetch J, Rodriguez A, Jeremitsky E. Characteristics and outcomes of trauma patients with ICU lengths of stay 30 days and greater: a seven-year retrospective study. Crit Care 2009;13:R154.

29 Hermans G, Van Aerde N, Meersseman P, Van Mechelen H, Debaveye Y, Wilmer A, Gunst J, Casaer MP, Dubois J, Wouters P, et al. Five-Year mortality and morbidity impact of prolonged versus brief ICU stay: a propensity score matched cohort study. Thorax 2019:74:1037-45.
30 Archer KR, Castillo RC, Wegener ST, Abraham CM, Obremskey WT. Pain and satisfaction in hospitalized trauma patients: the importance of self-efficacy and psychological distress. J Trauma Acute Care Surg 2012;72:1068-77.

31 Morrison SR, Magaziner J, McLaughlin MA, Orosz G, Silberzweig SB, Koval KJ, Siu AL. The impact of post-operative pain on outcomes following hip fracture. Pain 2003;103:303-11.

32 Lenze EJ, Munin MC, Quear T, Dew MA, Rogers JC, Begley AE, Reynolds CF. Significance of poor patient participation in physical and occupational therapy for functional outcome and length of stay. Arch Phys Med Rehabil 2004;85:1599-601.

33 Jang BN, Lee HJ, Joo JH, Park E-C, Jang S-I. Association between health behaviours and depression: findings from a national cross-sectional study in South Korea. BMC Psychiatry 2020;20:238.

34 Sadr Azodi O, Bellocco R, Eriksson K, Adami J. The impact of tobacco use and body mass index on the length of stay in hospital and the risk of post-operative complications among patients undergoing total hip replacement. J Bone Joint Surg Br 2006:88:1316-20.

35 Ringdal M, Plos K, Lundberg D, Johansson L, Bergbom I. Outcome after injury: memories, health-related quality of life, anxiety, and symptoms of depression after intensive care. J Trauma 2009;66:1226-33.

36 Griffiths SE, Tandon U, Treml J, Jackson TA, et al. Delirium in trauma. Trauma 2014:16:87-92.

37 Kim MM, Barnato AE, Angus DC, Fleisher LA, Fleisher LF, Kahn JM. The effect of multidisciplinary care teams on intensive care unit mortality. Arch Intern Med 2010;170:369-76

38 Huber-Lang M, Lambris JD, Ward PA. Innate immune responses to trauma. Nat Immunol 2018;19:327-41.

39 Dharap SB, Ekhande SV. An observational study of incidence, risk factors \& outcome of systemic inflammatory response \& organ dysfunction following major trauma. Indian J Med Res 2017; 146:346-53.

40 Sotelo JL, Nemeroff CB. Depression as a systemic disease. Pers Med Psychiatry 2017:1-2:11-25

41 Maly RC, Umezawa Y, Leake B, Silliman RA. Determinants of participation in treatment decision-making by older breast cancer patients. Breast Cancer Res Treat 2004;85:201-9.

42 Foster C, Haviland J, Winter J, Grimmett C, Chivers Seymour K, Batehup L, Calman L, Corner J, Din A, Fenlon D, et al. Pre-Surgery depression and confidence to manage problems predict recovery trajectories of health and wellbeing in the first two years following colorectal cancer: results from the Crew cohort study. PLoS One 2016;11:e0155434.

43 Milanovic M, Ayukawa E, Usyatynsky A, Holshausen K, Bowie CR. Self efficacy in depression: bridging the gap between competence and real world functioning. J Nerv Ment Dis 2018:206:350-5.

44 Muris P. Relationships between self-efficacy and symptoms of anxiety disorders and depression in a normal adolescent sample. Pers Individ Dif 2002;32:337-48.

45 Pfeifer R, Pape H-C. Missed injuries in trauma patients: a literature review. Patient Saf Surg 2008;2:20.

46 Auerbach AD, Vittinghoff E, Maselli J, Pekow PS, Young JQ, Lindenauer PK. Perioperative use of selective serotonin reuptake inhibitors and risks for adverse outcomes of surgery. JAMA Intern Med 2013:173:1075-81.

47 Mrkobrada M, Hackam DG. Selective serotonin reuptake inhibitors and surgery: to hold or not to hold, that is the question: comment on "Perioperative use of selective serotonin reuptake inhibitors and risks for adverse outcomes of surgery". JAMA Intern Med 2013;173:1082-3.

48 Bouamra O, Jacques R, Edwards A, Yates DW, Lawrence T, Jenks T, Woodford M, Lecky F. Prediction modelling for trauma using comorbidity and 'true' 30-day outcome. Emerg Med J 2015;32:933-8.

49 Moran CG, Lecky F, Bouamra O, et al. Changing the System - Major Trauma Patients and Their Outcomes in the NHS (England) 2008-17. EClinicalMedicine 2018:23:13-21.

50 National Research Ethics Service (NRES). NHS Research Ethics Committee Decision Tool. http://www.hra-decisiontools.org.uk/research/ (10 Jan 2021). 